\title{
Transtorno de Apego Reativo em crianças institucionalizadas
}

\author{
Reactive Attachment Disorder in institutionalized children
}

\author{
Geraldo Antonio Fiamenghi Junior ${ }^{[0]}$, Renata Hottum Melani ${ }^{[b]}$, Sueli Galego de Carvalho ${ }^{[c]}$
}

\footnotetext{
${ }^{[a]}$ Doutorado em Psicologia pela University of Edinburgh, professor adjunto da Universidade Presbiteriana Mackenzie Centro Universitário Nossa Senhora do Patrocínio (CEUNSP), São Paulo, SP - Brasil, e-mail: gfiamenghi@yahoo.com

${ }^{[b]}$ Mestrando em Distúrbio do Desenvolvimento pela Universidade Mackenzie, psicopedagoga do Instituto Sedes Sapientiae, Universidade Presbiteriana Mackenzie, São Paulo,

SP - Brasil.

${ }^{[c]}$ Doutorado em Administração de Empresas pela Universidade Presbiteriana Mackenzie, professora adjunta do curso de Psicologia, vinculado ao Centro de Ciências Biológicas e da Saúde da Universidade Presbiteriana Mackenzie, São Paulo, SP - Brasil.
}

Recebido: 09/03/2011 Received: 03/09/2011

Aprovado: 26/04/2011 Approved: 04/26/2011

\section{Resumo}

O Transtorno de Apego Reativo é caracterizado pelo desenvolvimento de formas perturbadas e inadequadas de estabelecer relacionamentos, geralmente por causa de uma história de maus tratos. Esta pesquisa teve como objetivo investigar sinais de Transtorno de Apego Reativo em crianças institucionalizadas. Portanto, 25 crianças (15 meninos e 10 meninas), com 4 a 12 anos de idade, vivendo em um abrigo na cidade de São Paulo, foram avaliadas utilizando o Desenho da Figura Humana (DFH), baseado nos 30 indicadores emocionais propostos por Koppitz. Os resultados mostraram que as crianças demonstraram timidez, afastamento, assim, como baixo interesse social, sentimentos de imobilidade, desesperança e agressão aberta em relação ao ambiente, inadequação e culpa. Algumas das crianças apresentaram sinais significativos do Transtorno de Apego Reativo, principalmente do tipo inibido. Os critérios diagnósticos para o transtorno ainda necessitam precisão e mais pesquisas utilizando o DFH. Contudo, sugere-se que melhoras no ambiente das crianças, especialmente com as pessoas responsáveis por seu cuidado direto possam remediar os sintomas, assim como prevenir futuros problemas.

Palavras-chave: Transtorno de Apego Reativo. Desenho da figura humana. Institucionalização. Criança.

\section{Abstract}

Reactive Attachment Disorder (RAD) is characterized by disturbed and developmentally inappropriate ways of socially relating normally due to a history of maltreatment. This research aimed to investigate signs of RAD in institutionalized children. Thus, 25 children (15 boys and 10 girls), aged 4 to 12 years old, living in a shelter home in Sao Paulo (Brazil) were assessed, using the Human Figure Drawing (HFD), based on Koppitz's 30 emotional indicators. Results showed that children presented shyness, withdrawal, as well as poor social interest, feelings of immobility, despair, open aggressiveness towards the environment and inadequacy or guilt. Some of those children presented significant signs of RAD, especially of the inhibited type. Diagnosis criteria for the disorder are still lacking precision, and more research using the HFD is needed, although it's suggested that improvements in children environment, especially with staff responsible for direct care, could remediate symptoms as well as prevent future psychological problems.

Keywords: Reactive Attachment Disorder. Human figure drawing. Institutionalization. Child.

Psicol. Argum. 2012 jul./set., 30(70), 431-439 


\section{Introdução}

0 vínculo afetivo (attachment) desenvolve-se na infância com o objetivo de obter proximidade com a figura materna; esse comportamento continua durante toda vida (Bowlby, 1990) e é indispensável para vida social, pois favorece a capacidade de manter relações. Segundo Barros e Fiamenghi (2007), mães que são insensíveis e negligentes às necessidades de seus filhos acabam por gerar nas crianças insegurança, tanto em relação à própria mãe, quanto em relação aos outros. Quando as crianças têm suas necessidades de afeto, trocas subjetivas e cuidados com higiene e alimentação atendidas tornam-se confiantes e desenvolvem-se emocional, física e intelectualmente de forma saudável. Siqueira e Dell'Aglio (2006) assinalam que crianças institucionalizadas, por longos períodos, apresentam dificuldades na sociabilidade e na manutenção de vínculos afetivos na vida adulta. Ao estudarem crianças e adolescentes em situação de rua, Paludo e Koller (2005) observam que, a princípio, a situação de rua dá a essas crianças e adolescentes uma sensação de 'liberdade', e de dimensão lúdica; entretanto, com o passar do tempo, se transforma em vivências dolorosas da violência física, sexual e moral. Observam, ainda, que essas crianças e adolescentes apresentam sentimento de rejeição e de abandono, além de pobreza afetiva evidenciada pela falta de empatia e trocas de carinho. Scherer e Scherer (2000) correlacionam os maus tratos à maior propensão a uma vida criminosa, uso de drogas, automutilação e comportamento suicida, psicoses e dissociações, problemas nos relacionamentos interpessoais e vocacionais. Após o abrigamento, há uma grande chance de essa criança ser abandonada na instituição, porque os abrigos não estimulam a oportunidade da continuidade da relação entre o abrigado e a família (Weber, 1995). Quando abrigadas, as crianças passam por um processo de 'mutilação' de sua identidade, pois a instituição afasta o indivíduo da sociedade. Logo quando é admitida no abrigo, deve guardar seus objetos pessoais, cortar o cabelo e colocar as roupas que a instituição oferece, deve ter conhecimento das regras do local e ainda se ajustar à rotina do abrigo que, em geral, é muito diferente da rotina de uma casa. Toda disciplina que o abrigo impõe só distancia um vínculo afetivo efetivo entre abrigados e profissionais (Azôr \& Vectoré, 2008). Parreira e Justo (2005) observam que os abrigos causam nas crianças e adolescentes uma percepção do vínculo como algo temporário e instável. Abreu (2000) identifica que crianças e adolescentes abrigadas apresentam maiores chances de desenvolver transtornos psiquiátricos do que as que vivem com suas famílias. Segundo Barros e Fiamenghi (2007), os efeitos que o abrigamento traz para crianças não acontecem apenas pela separação da mãe, mas também pelo despreparo e falta de qualidade da instituição onde a criança é deixada. Pereira e Costa (2004) afirmam que os sujeitos constroem uma imagem de família abandonada ligada à exclusão social e ao rompimento dos vínculos afetivos, isto é, uma família abandonada pelo Estado, sem acesso a recursos de educação, saúde e moradia. Prada et al. (2007) compararam os abrigos e casa-lar, percebendo que, nas duas formas de institucionalização, existem regras rigorosas e disciplinadoras. Entretanto, nos abrigos, é comum a punição física, enquanto, nas casas, a punição delimita à retirada das atividades prazerosas. A maior diferença observada é na preservação da individualidade, pois, nos abrigos, as crianças já não possuíam mais objetos trazidos de casa, nem armários ou roupas individuais, enquanto que, na casa-lar, todas as crianças tinham objetos pessoais e armários com suas roupas e brinquedos próprios. Concluem que a individualidade deve ser preservada, para que as crianças e jovens possam se perceber enquanto seres únicos e importantes. Alexandre e Vieira (2004) estudaram a relação de apego em crianças abrigadas e concluíram que essas crianças se apegam a algum amigo da instituição e este passa a representar para elas a figura de apego. Perceberam que irmãos mais velhos demonstram preocupação com os mais novos. Convivendo com o grupo, as crianças ressignificam seus mundos, reciclam suas emoções e reinventam a realidade. Os autores observaram que as crianças demonstram desejo de voltarem ao seu lar e de serem adotadas, isto é, de terem uma família.

A característica principal do Transtorno de Apego Reativo é uma "ligação social perturbada e inadequada, com início aos 5 anos de idade e associada ao recebimento de cuidados amplamente patológicos" (APA, 1995, F.94, p. 384) e pode apresentar-se como tipo inibido (fracassos em iniciar ou responder a interações sociais de forma adequada e esperada a seu nível de desenvolvimento; padrão de respostas excessivamente inibidas, hipervigilantes, ou altamente ambivalentes), ou desinibido (sociabilidade 
indiscriminada ou falta de seletividade na escolha das figuras de vinculação). 0 Transtorno de Apego Reativo não satisfaz os critérios para um transtorno invasivo do desenvolvimento; o curso pode variar dependendo de fatores individuais tanto da criança quanto de seus responsáveis, da gravidade e da duração da privação psicossocial associada, bem como da natureza da intervenção. Segundo Smyke et al. (2002), uma das dificuldades em compreender os efeitos do cuidado institucional sobre o transtorno está ligada aos diagnósticos só ocorrerem após a adoção. Para Heller et al. (2006), o diagnóstico e tratamento do Transtorno de Apego Reativo na Infância deveriam ocorrer na primeira infância. Entretanto percebe-se que a realidade é diferente, pois as crianças institucionalizadas ou com história de maus tratos demoram a serem diagnosticadas. Isso se dá pela escassez de meios de avaliação. Os autores também analisaram o desenvolvimento e tratamento das crianças diagnosticadas. Levantam que as dificuldades em aplicar os critérios estabelecidos pelo DSM-IV são a razão principal pela falta de investigação e pesquisa sobre o transtorno. Chegam a sugerir que estudos existentes concluem que esses critérios devam ser expandidos. Para Heller et al. (2006), o tipo mais encontrado nas instituições é o desinibido. Schwartz e Davis (2006) concluem que crianças com traumas e rupturas relacionais precoces na primeira relação (mãe-bebê) podem vir a ser diagnosticadas com o transtorno; entretanto o diagnóstico estende-se para além do âmbito da relação mãe-bebê e se amplia para outros contextos sociais anormais. Os autores escrevem que a característica predominante do transtorno é a presença de acentuada perturbação no desenvolvimento do relacionamento social, na maioria dos contextos, com início antes dos 5 anos e associa-se com patogenia do cuidado. 0 que o diferencia dos demais transtornos é a história de maus tratos. A investigação revela também que as crianças pesquisadas com o transtorno externalizam comportamentos agressivos. São crianças que têm como marca a dificuldade de desenvolver o afeto, em suas relações demonstram ter insegurança, mantêm uma relação pobre e apresentam problemas de adaptação na escola. Essas crianças ainda apresentam reduzida autoestima, hiperatividade e baixa tolerância à frustração. Isso se dá porque não experimentaram a segurança do vínculo com a mãe, crescem num mundo muitas vezes caótico e negligente, o que reflete na capacidade de lidar com as emoções e comportamento, muitas vezes essa aparece fora de controle. Schwartz e Davis (2006) concluem que as crianças com o transtorno estão mais voltadas para preocupações internas de segurança e confiança e a necessidade de sobrevivência, dada a sua história de maus tratos; com essa invasão de sentimento elas não conseguem tirar proveito da aprendizagem. Boris et al. (2004) apontam que grande parte da literatura científica sobre o transtorno consiste em relatos de caso e o tema frequente desses relatos é a dificuldade de aplicar os critérios do DSM-IV. Os estudos de Mukaddes et al. (2000) tiveram como objetivo demonstrar as boas respostas dadas ao tratamento do transtorno e a importância disso para o diagnóstico diferencial de Transtorno Invasivo do Desenvolvimento (TID). Concluem que os comportamentos encontrados nessas crianças não se dão por causa da separação em si da figura materna, mas à qualidade a assistência prestada e à falta de estímulos, corroborando a pesquisa de Barros e Fiamenghi (2007), que enfatiza uma necessidade dos abrigos de melhor treinamento e envolvimento da equipe que cuida das crianças. Os estudos de Smyke et al. (2002) realçam que a dificuldade dos cuidadores em investirem emocionalmente nas crianças está ligada à falta de recurso dos abrigos; como as instituições, em geral, não têm número suficiente de funcionários. Eles trabalham em turnos e são responsáveis por uma grande quantidade de crianças. Zeanah e Smyke (2008) acrescentam que um TID se desenvolveria mesmo em um ambiente acolhedor e que o Transtorno Reativo do Afeto se dá em situações onde o ambiente é pouco acolhedor e favorável. Mukaddes et al. (2000) percebem que a dificuldade de comunicação social e atraso na linguagem podem causar problemas no diagnóstico diferencial, concluindo que a diferenciação é crucial no diagnóstico e tratamento do transtorno. Explicam ainda que o estudo realizado sobre Transtorno Reativo de Apego na Infância em população clínica é limitado, e os profissionais muitas vezes são inexperientes em avaliação e tratamento. Aceitam que a diferença entre Transtorno Reativo do Apego na Infância e Transtorno Invasivo do Desenvolvimento está no fato do primeiro ser reversível e responder rapidamente a uma intervenção precoce e ser uma consequência da patogenicidade do cuidado. Smyke et al. (2002) observam que as estereotipias encontradas nas crianças institucionalizadas podem estar associadas à acentuada negligência. Acreditam que num ambiente com tão pouca estimulação as 
estereotipias podem servir como um tipo de autoestimulação. Movimentos repetitivos também têm a função de uma tentativa tranquilizante, quando os adultos não estão disponíveis para proporcionar afeto. Ainda apontam que as estereotipias podem refletir uma frustração da criança, principalmente naquelas que não têm uma boa comunicação verbal. Tais comportamentos foram percebidos nos momentos em que existe alguma ameaça do meio externo, que gere ansiedade. Zeanah e Smyke (2008) apontam que as pesquisas sobre os transtornos só ganharam força no ano de 1980; entretanto acrescentam que os estudos de Bowlby são anteriores a essa data. Outro ponto interessante que os autores levantam é que crianças institucionalizadas, quando colocadas em famílias, parecem ter reduzidos os sintomas emocionais do transtorno, pois começam a viver em ambientes onde recebem afeto e maiores cuidados.

O Desenho da Figura Humana (DFH) é um instrumento comumente utilizado entre os profissionais de Psicologia de diferentes países, principalmente nos ibero-latinos, pelo baixo custo do instrumento e pela falta de validação de outras técnicas (Wechsler \& Schelini, 2002; Sisto, 2006). 0 sistema de Koppitz é o mais apropriado para a avaliação do desenvolvimento emocional e, comparando a avaliação do desenho com dados obtidos por outros instrumentos, podem-se confirmar os resultados (Tharinger \& Stark, 1990). Segundo Lim-Hui e Slaugther (2007), os desenhos das crianças, especialmente os da figura humana, têm sido o centro das atenções durante décadas, pois refletem uma série de variáveis psicológicas, incluindo maturidade intelectual, personalidade, pensamento e emoção. Concluem, ainda, que, pelos desenhos, somos capazes de perceber o desenvolvimento infantil tanto na área cognitiva como nos processos de socialização. Laak et al. (2005) fizeram um estudo para avaliar se o DFH era um teste capaz de indicar características de personalidade e adaptação ao meio e perceberam que os desenhos têm uma ligação direta com a expressão simbólica da personalidade das crianças e que este é um dos dez principais instrumentos utilizados pelos profissionais da Psicologia. Ainda afirmam que a analise global enfatiza a avaliação específica das características do conteúdo e da qualidade emocional dos desenhos, assim como, a adaptação social e de como esse emocional atravessa as relações e concluem que é um instrumento adequado para avaliar perturbações já experimentadas na infância.
O desenho tem um valor terapêutico em si mesmo e constitui-se em condição ótima para projeção da personalidade, possibilitando a manifestação mais direta de aspectos profundos e inconscientes; isso porque, sendo um meio menos usual de comunicação do que a linguagem, tem um conteúdo simbólico menos reconhecido. Além da projeção, mecanismos como identificação e introjeção podem eventualmente se manifestar, mas é certo que a expressão e a adaptação constituem dois importantes processos que têm lugar quando o desenho é produzido (Van Kolck, 1994).

Essa pesquisa exploratória e qualitativa, portanto, teve como objetivo utilizar o teste do DFH, segundo a análise de Koppitz (1969), como forma de identificar sinais do Transtorno de Apego Reativo na Infância em crianças abrigadas.

\section{Método}

\section{Participantes}

Vinte e cinco crianças (15 do sexo masculino e dez do feminino), com idades entre 4 a 12 anos, que vivem em um abrigo na região metropolitana de São Paulo. A escolha dessa faixa etária deveu-se ao fato de que as crianças já alcançaram um nível de escolaridade mínima e poderiam produzir desenhos mais estruturados para a análise. A diferença no número de meninas e meninos se deve ao fato de que existem mais meninos abrigados do que meninas. A identidade dos participantes foi mantida sob sigilo, os participantes poderiam retirar-se do estudo a qualquer momento. A pesquisa ofereceu riscos mínimos aos participantes, sendo os resultados utilizados apenas para fins de pesquisa científica. Por se tratar de crianças abrigadas, muitas afastadas das famílias por questões de abuso e maus tratos, as informações pessoais não foram fornecidas pela instituição, como uma tentativa de preservar o sigilo. Assim, dados sobre as famílias, condições de saúde física e/ou psicológica das crianças e tempo de abrigamento não foram disponibilizadas.

Local

O estudo foi realizado numa instituição de abrigamento para menores, situada na região metropolitana de São Paulo. Na instituição, residem 120 crianças, 
de 0 a 17 anos, meninos e meninas, separados em residências, cuja característica principal é manter os agrupamentos familiares reunidos no mesmo local. Por isso, não é feita divisão por faixa etária nas casas.

\section{Instrumentos e procedimento}

Após o contato com a instituição e apresentação da Carta de Intenções à Instituição e assinatura do Termo de Consentimento Livre e Esclarecido, foram agendadas visitas para a aplicação do instrumento. Foi utilizado como instrumento o Desenho da Figura Humana (DFH). 0 desenho foi aplicado individualmente aos participantes, que puderam utilizar lápis grafite e borracha. $\mathrm{O}$ tempo não foi previamente estipulado. As instruções dadas foram: "Faça um desenho de uma pessoa". O projeto foi aprovado pelo Comitê de Ética em Pesquisa com Humanos da Universidade, sob n. CEP/ UPM 1047/05/2008 e CAAE n. 0024.0.272.000-08.

\section{Resultados}

Os desenhos foram analisados segundo a interpretação proposta por Koppitz (1968). Os resultados foram comparados com os critérios do DSM-IV para Transtorno de Apego Reativo e discutidos de acordo com a literatura sobre o tema.

Koppitz (1968) propõe 30 indicadores emocionais, quando se utilizam Desenhos da Figura Humana. Primeiramente, serão apresentados os resultados individuais dos desenhos das crianças, em um quadro dividido por sexo e idade. Em seguida, serão discutidas as análises realizadas. Os nomes foram modificados, mantendo-se apenas uma inicial para preservar o sigilo quanto à identidade das crianças.

A Tabela I a seguir mostra os resultados por sexo, idade, expondo a análise dos desenhos, segundo os 30 indicadores propostos por Koppitz (1968).

Tabela 1 - Resultados por sexo e faixa etária

(Continua)

\begin{tabular}{llll}
\hline Criança & Sexo & Idade & \multicolumn{1}{c}{ Análise dos desenhos } \\
\hline F. & fem. & 4 a. & $\begin{array}{l}\text { Apesar do desejo de aquisição pes- } \\
\text { soal e sucesso se mostra falta de } \\
\end{array}$ \\
& & & $\begin{array}{l}\text { liderança, insegurança e timidez. } \\
\text { Parece ter dificuldade em abrir-se } \\
\end{array}$ \\
& & & para o mundo e para os outros. \\
& & Possui um comportamento agressi- \\
& & vo e acting- out com as mãos. \\
\hline
\end{tabular}

Tabela 1 - Resultados por sexo e faixa etária

(Continua)

\begin{tabular}{|c|c|c|c|}
\hline Criança & Sexo & Idade & Análise dos desenhos \\
\hline $\mathrm{J}$. & fem. & 4 a. & $\begin{array}{l}\text { Bastante insegura e depressiva. } \\
\text { Socialmente se coloca de forma } \\
\text { a isolar-se, entretanto mostra } \\
\text { tendência a negar problemas re- } \\
\text { cusando-se a enfrentar o mundo } \\
\text { fugindo para a fantasia. Mostra } \\
\text { recusa ou mesmo inabilidade } \\
\text { para comunicar-se. Demonstra } \\
\text { pouco interesse social, sente-se } \\
\text { desamparada. Parece sentir-se } \\
\text { culpada diante do seu comporta- } \\
\text { mento social }\end{array}$ \\
\hline L. & fem. & 4 a. & $\begin{array}{l}\text { Bastante ansiosa e com conflitos } \\
\text { na área da sexualidade. Tímida } \\
\text { e com falta de agressividade. } \\
\text { Demonstra pouco interesse } \\
\text { social. Sente-se desamparada e } \\
\text { com pouca habilidade para agir } \\
\text { de forma confiante }\end{array}$ \\
\hline D. & fem. & $5 \mathrm{a}$. & $\begin{array}{l}\text { Criança tímida com sentimento } \\
\text { de inadequação ou culpa por se } \\
\text { sentir incapaz de agir correta- } \\
\text { mente ou mesmo de agir em ge- } \\
\text { ral. Possui falta de agressividade } \\
\text { e um afastamento do ambiente, } \\
\text { demonstrando timidez, ansieda- } \\
\text { de e resistência passiva. Pouco } \\
\text { interesse pelo ambiente social e } \\
\text { recusa-se a comunicar-se com os } \\
\text { outros. Grave imaturidade graças } \\
\text { ao atraso do desenvolvimento. } \\
\text { Pode-se suspeitar de transtorno } \\
\text { emocional com ansiedade corpo- } \\
\text { ral aguda ou medo de castração. }\end{array}$ \\
\hline $\mathrm{R}$. & fem. & 5 a. & $\begin{array}{l}\text { Pouca coordenação motora e } \\
\text { pouco controle dos impulsos. } \\
\text { Agressividade é voltada para } \\
\text { o ambiente. Seu interesse pelo } \\
\text { social é reduzido, possuindo sen- } \\
\text { timento de imobilidade, desam- } \\
\text { paro, uma inabilidade de seguir } \\
\text { em frente de forma confiante. }\end{array}$ \\
\hline P. & fem. & 6 a. & $\begin{array}{l}\text { Instabilidade generalizada, falta } \\
\text { de equilíbrio e de segurança. } \\
\text { Sujeito é tímido, possui falta de } \\
\text { agressividade e afastamento } \\
\text { social, pois parece ter reduzido o } \\
\text { interesse sobre o meio. Sente- } \\
\text {-se desamparada e sentimento } \\
\text { de inabilidade agir de forma } \\
\text { confiante. }\end{array}$ \\
\hline L. & fem. & 7 a. & $\begin{array}{l}\text { Comportamento agressivo e } \\
\text { acting-out com as mãos. }\end{array}$ \\
\hline
\end{tabular}


Tabela 1 - Resultados por sexo e faixa etária

(Continua)

\begin{tabular}{|c|c|c|c|}
\hline Criança & Sexo & Idade & Análise dos desenhos \\
\hline D. & fem. & 9 a. & $\begin{array}{l}\text { Instabilidade generalizada e falta } \\
\text { de equilíbrio e falta de segurança } \\
\text { generalizada, que se comprova } \\
\text { com uma insegurança e ansie- } \\
\text { dade intensa. Sua agressividade } \\
\text { é voltada a si, não a direcionan- } \\
\text { do para o meio, sendo incapaz } \\
\text { de atacar as pessoas. Parece } \\
\text { sentir-se ameaçada pelo mundo, } \\
\text { principalmente pelos adultos, } \\
\text { especialmente pelos pais. }\end{array}$ \\
\hline J. & fem. & $12 \mathrm{a}$. & $\begin{array}{l}\text { Bastante agressiva conduzin- } \\
\text { do essa energia para o meio e } \\
\text { utilizando de acting- out com as } \\
\text { mãos. Possui um autoconceito } \\
\text { reduzido e um sentimento de } \\
\text { forte inadequação. }\end{array}$ \\
\hline I. & fem. & $12 \mathrm{a}$. & $\begin{array}{l}\text { Sua agressividade é aberta em } \\
\text { relação ao ambiente. Possui } \\
\text { indicativos de tensão ou tentativa } \\
\text { de controlar impulsos sexuais ou } \\
\text { mesmo demonstra medo de um } \\
\text { ataque sexual pelos outros. }\end{array}$ \\
\hline $\mathrm{R}$. & masc. & 4 a. & $\begin{array}{l}\text { Sente-se inadequado intelectual- } \\
\text { mente, sua coordenação motora } \\
\text { é reduzida. Coloca-se no meio de } \\
\text { forma agressiva, o que gera culpa. } \\
\text { Mostra pouco interesse pelo } \\
\text { social afastando-se e isolando- } \\
\text {-se. Recusa-se em comunicar-se } \\
\text { com os outros. Tímido, ansioso } \\
\text { e inseguro. Demonstra tensão } \\
\text { e uma tentativa de controlar os } \\
\text { impulsos sexuais ou medo de um } \\
\text { ataque sexual pelos outros. Tenta } \\
\text { negar seus problemas recusando } \\
\text { a enfrentar o mundo e escapando } \\
\text { para a fantasia. }\end{array}$ \\
\hline D. & masc. & $5 \mathrm{a}$. & $\begin{array}{l}\text { Apresenta dificuldade de abrir-se } \\
\text { para o mundo e para os outros. } \\
\text { Bem comportada e tímida. Mos- } \\
\text { tra ainda pouco interesse social, } \\
\text { sentimento de imobilidade e } \\
\text { desamparo. Sua insegurança gera } \\
\text { um sentimento de inabilidade. } \\
\text { Apresenta ainda grave imaturida- } \\
\text { de graças ao atraso no desenvol- } \\
\text { vimento e ansiedade corporal } \\
\text { aguda ou medo de castração. Sua } \\
\text { coordenação motora é reduzida } \\
\text { com impulsividade. }\end{array}$ \\
\hline
\end{tabular}

Tabela 1 - Resultados por sexo e faixa etária

(Continua)

\begin{tabular}{|c|c|c|c|}
\hline Criança & Sexo & Idade & Análise dos desenhos \\
\hline E. & masc. & 5 a. & $\begin{array}{l}\text { Apresenta atraso no desen- } \\
\text { volvimento. Criança ansiosa e } \\
\text { culpada por seu comportamento } \\
\text { socialmente inadequado, envol- } \\
\text { vendo ações com mãos e braços. } \\
\text { Demonstra inabilidade ou mesmo } \\
\text { recusa em comunicar-se com os } \\
\text { outros, reduzido interesse social. } \\
\text { Usa de resistência passiva com } \\
\text { falta de agressividade. Sente-se } \\
\text { desamparado. }\end{array}$ \\
\hline G. & masc. & 5 a. & $\begin{array}{l}\text { Criança bastante ansiosa e } \\
\text { insegura. Aparece culpada por } \\
\text { seu agir inadequado. Recusa-se } \\
\text { a comunicar-se com os outros } \\
\text { apresentando afastamento e ti- } \\
\text { midez, demonstrando resistência } \\
\text { passiva. Apresenta ainda grave } \\
\text { imaturidade graças ao atraso no } \\
\text { desenvolvimento. Possivelmente, } \\
\text { apresenta transtorno emocional } \\
\text { com ansiedade corporal aguda ou } \\
\text { medo da castração. }\end{array}$ \\
\hline L. & masc. & 5 a. & $\begin{array}{l}\text { Insegurança, timidez e ansiedade } \\
\text { intensa. }\end{array}$ \\
\hline $\mathrm{R}$. & masc. & 5 a. & $\begin{array}{l}\text { Sua agressividade está voltada } \\
\text { para o ambiente. }\end{array}$ \\
\hline L. & masc. & 6 a. & $\begin{array}{l}\text { Dificuldade em abrir-se para o } \\
\text { mundo e para os outros. É tímida } \\
\text { e bem comportada, com falta de } \\
\text { agressividade e liderança, mas } \\
\text { ainda tem preservado o desejo } \\
\text { de sucesso e aquisições pessoais. } \\
\text { Reduzida coordenação motora } \\
\text { e impulsividade. Reflete ainda } \\
\text { insegurança e depressão. }\end{array}$ \\
\hline E. & masc. & 7 a. & $\begin{array}{l}\text { Apresenta-se inseguro e depres- } \\
\text { sivo. Sua agressividade é voltada } \\
\text { para o ambiente. Pouco interesse } \\
\text { social e timidez, com sentimentos } \\
\text { de imobilidade e desamparo. } \\
\text { Pouca confiança para agir, pois se } \\
\text { sente inábil. }\end{array}$ \\
\hline A. & masc. & 8 a. & $\begin{array}{l}\text { Sentimento de inadequação } \\
\text { intelectual. Sua agressivida- } \\
\text { de é voltada para o ambiente. } \\
\text { Demonstra tensão e tentativa de } \\
\text { controlar impulsos sexuais, ou } \\
\text { mesmo medo de ataque sexual } \\
\text { pelos outros. }\end{array}$ \\
\hline
\end{tabular}


Tabela 1 - Resultados por sexo e faixa etária

(Conclusão)

\begin{tabular}{|c|c|c|c|}
\hline Criança & Sexo & Idade & Análise dos desenhos \\
\hline F. & masc. & 8 a. & $\begin{array}{l}\text { Apresenta-se tímido e com pouco } \\
\text { interesse no social. Afasta-se do } \\
\text { meio. Insegurança e desamparo. } \\
\text { Sente-se inábil para agir de forma } \\
\text { confiante. }\end{array}$ \\
\hline $\mathrm{L}$. & masc. & 8 a. & $\begin{array}{l}\text { Demonstra dificuldade em } \\
\text { abrir-se para o mundo e para } \\
\text { os outros. Apesar de ter pou- } \\
\text { ca capacidade de liderança e } \\
\text { agressividade, preserva ainda o } \\
\text { desejo de sucesso e aquisições } \\
\text { pessoais. Sente-se inadequado e } \\
\text { culpado com sua atitude social. } \\
\text { Mostra muita ansiedade corporal, } \\
\text { mostrando conflito e medo } \\
\text { principalmente nas áreas sexuais. } \\
\text { Provavelmente pode-se identifi- } \\
\text { car psicopatologia nessa área e } \\
\text { reduzido controle de impulsos. }\end{array}$ \\
\hline P. & masc. & 8 a. & $\begin{array}{l}\text { Agressividade aberta em relação } \\
\text { ao meio. }\end{array}$ \\
\hline A. & masc. & 8 a. & $\begin{array}{l}\text { Impulsividade e coordenação } \\
\text { motora reduzida. Possui sentimen- } \\
\text { to de inadequação intelectual, com } \\
\text { agressividade voltada ao ambiente. } \\
\text { Sente-se inadequado no meio, com } \\
\text { um autoconceito reduzido. Per- } \\
\text { cebe-se diferente em relação aos } \\
\text { outros como se não fosse humano. } \\
\text { Seu interesse social é reduzido, } \\
\text { sente-se desamparado e incapaz de } \\
\text { atuar de forma confiante. }\end{array}$ \\
\hline V. & masc. & 8 a. & $\begin{array}{l}\text { Sua agressividade é aberta em } \\
\text { relação ao ambiente. Sente-se } \\
\text { inadequado ou culpado sobre a } \\
\text { incapacidade de agir corretamen- } \\
\text { te. Pouco interesse social, timidez } \\
\text { e sentimento de desamparo. } \\
\text { Coloca-se como alguém que não } \\
\text { possui habilidades para seguir } \\
\text { em frente de forma confiante. }\end{array}$ \\
\hline J. & masc. & 9 a. & $\begin{array}{l}\text { Sentimento intenso de inadequa- } \\
\text { ção intelectual. Sua agressividade } \\
\text { é aberta em relação ao ambiente, } \\
\text { demonstrando assim compor- } \\
\text { tamentos agressivos. Sente } \\
\text { bastante inadequação e reduzido } \\
\text { autoconceito. Percebe-se como } \\
\text { alguém ridículo, que não é aceito } \\
\text { socialmente. }\end{array}$ \\
\hline
\end{tabular}

Fonte: Dados da pesquisa.
Sinais importantes foram observados, indicando que algumas das crianças da amostra necessitam ser mais direta e atentamente observadas, pois $48 \%$ de todas as crianças foram caracterizadas por timidez, afastamento, falta de agressividade, assim como baixo interesse social, sentimentos de imobilidade, desesperança e incapacidade de agir com confiança, segundo os critérios propostos por Koppitz (1968).

Outro traço observado em $44 \%$ das crianças foi uma agressão aberta em relação ao ambiente e $40 \%$ das crianças também mostraram sinais de sentimentos de inadequação ou culpa por não serem capazes de agir adequadamente.

Decidimos, então, reagrupar os resultados em duas categorias mais amplas, dificuldades de socialização e dificuldades emocionais, que poderiam explicar semelhanças na análise (Tabela 2).

As duas categorias podem auxiliar-nos a comparar os indicadores para Transtorno de Apego Reativo (APA, 2000) com a análise do DFH.

As categorias mostram que existe uma incidência de traços do tipo inibido do transtorno, que é caracterizado por falhas em iniciar e manter interações sociais e um padrão de respostas inibidas em relação ao ambiente. Outro critério do Transtorno Reativo de Apego relaciona-o com cuidados patológicos na infância, o que é evidente em nossa amostra, pois as crianças foram separadas dos pais devido a maus tratos, negligência e abuso.

Nos desenhos, segundo os critérios de Koppitz (1968), foi percebido que essas crianças possuem um sentimento de desamparo e grande insegurança. Outro sentimento que chama a atenção foi o de sentirem-se ameaçados pelo mundo, principalmente por adultos, especialmente pelos seus pais, demonstrando, assim, que, de alguma forma, essas figuras que deveriam representar a segurança falharam.

Tabela 2 - Categorização dos resultados do DFH

\begin{tabular}{lc}
\hline \multicolumn{1}{c}{ CATEGORIAS } & FREQ \\
\hline $\begin{array}{l}\text { Dificuldades de socialização: incluindo } \\
\text { afastamento graças ao baixo interesse } \\
\text { social; culpa graças à inabilidade social; } \\
\text { agressividade (em relação aos outros ou ao } \\
\text { mundo); atraso no desenvolvimento motor. }\end{array}$ & 75 \\
$\begin{array}{l}\text { Dificuldades emocionais: incluindo deses- } \\
\text { perança; passividade; dificuldades sexuais; }\end{array}$ & 89 \\
ansiedade; fantasia; tensão.
\end{tabular}

Fonte: Dados da pesquisa. 


\section{Discussão}

Os resultados deste estudo podem ser explicados pelo fato que a institucionalização só dá conta das necessidades físicas da criança (alimentação, vestuário, abrigo), mas não consegue lidar com suas necessidades afetivas e morais (Siqueira \& Dell' Aglio, 2006). Outro aspecto a ser considerado refere-se à invisibilidade social à qual as crianças abandonadas estão sujeitas, sendo que as reações agressivas podem explicar as tentativas de demonstrar suas necessidades afetivas (Orionte \& Sousa, 2005), o que foi demonstrado pela presença de agressividade nos desenhos das crianças investigadas. De acordo com Bowlby (1979), cada vez que uma relação afetiva (attachment) é rompida, aparecem sentimentos de tristeza, ansiedade e raiva; tais sinais estão presentes nos desenhos de nossa amostra. Também observamos uma tendência de escapar para a fantasia, por causa de uma reduzida autoestima e falta de segurança, tendências normalmente presentes em crianças institucionalizadas, segundo os estudos de Weber (1995).

Os sentimentos de desamparo e insegurança evidenciados na análise dos desenhos podem ser explicados segundo Bowlby (1979), ao afirmar ser fundamental que as figuras representando segurança para as crianças sejam eficazes ao desempenhar seu papel. Por outro lado, a instabilidade das figuras que cuidam primariamente da criança é outro fator sugestivo no desenvolvimento dos sintomas do transtorno. De fato, o critério para diagnóstico diferencial de Transtorno de Apego Reativo em relação a outros transtornos é um histórico de maus tratos (Schwartz \& Davis, 2006; Zeanah \& Smyke, 2008).

\section{Considerações finais}

Embora houvesse tentativas de melhorar a qualidade de vida das crianças abrigadas no Brasil, a realidade institucional ainda é de despersonalização e punição. As crianças continuam a ter suas personalidades mutiladas e seus desejos reprimidos. Consequentemente, será muito provável que não consigam desenvolver plenamente suas habilidades como seres humanos.

Toda a literatura sobre Transtorno de Apego Reativo mostra que os sintomas desaparecem quando as crianças são colocadas em lares afetivos e com cuidados adequados. Portanto, é fundamental que as instituições preservem vínculos familiares e pessoais das crianças abrigadas, além de promover treinamento adequado à equipe responsável pelo cuidado com as crianças.

Aparentemente, o teste do Desenho da Figura Humana, avaliado segundo os critérios propostos por Koppitz (1968), é um instrumento eficaz para identificar sinais de Transtorno de Apego Reativo em crianças, embora devamos observar os resultados com cautela, apesar de quase metade das crianças da amostra apresentar alguns sinais do transtorno, especialmente do tipo inibido. Obviamente, mais estudos são necessários, com uma amostra mais ampla de crianças, para verificar a estabilidade dos resultados obtidos com esta amostra, que apresenta limites graças às condições impostas pela instituição quando da coleta de dados (nenhuma informação quanto ao tempo de institucionalização, motivos ou circunstâncias pessoais que levaram ao abrigamento).

Finalmente, a literatura mostra que os critérios utilizados pelo DSM-IV para o diagnóstico do Transtorno de Apego Reativo são superficiais.

Portanto, sugerimos a continuidade de pesquisas, comparando os resultados do DFH com outros testes projetivos, para verificar a fidedignidade do DFH para a avaliação do Transtorno de Apego Reativo na infância.

\section{Referências}

Abreu, S. R. (2002). Crianças e adolescentes em situações de risco no Brasil. Revista Brasileira de Psiquiatria, 24(1), 5-6.

American Psychiatric Association - APA. (2000). Diagnostic and Statistic Manual of Mental Disorders - DSM- IV (TR). Washington, DC: American Psychiatric Association.

Azôr, A. M., \& Vectoré, C. (2008). Abrigar e desabrigar: Conhecendo o papel das famílias nesse processo. Estudos de Psicologia, 25(1), 77-89.

Barros, R. C., \& Fiamenghi, G. A. (2007). Interações afetivas de crianças abrigadas: Um estudo etnográfico. Ciência \& Saúde Coletiva, 12(5), 1267-1276.

Boris, N. W., Fuselier, S. S. H., Smyke, A. T., Scheeringa, M. S., Heller, S. S., \& Zeanah. C. H. (2004). Comparing criteria for attachment disorders: Establishing reliability and validity in high risk samples. Academy of Child and Adolescent Psychiatry, 43(5), 568-578. 
Bowlby, J. (1979). The making and breaking of affectional bonds. London: Routledge.

Brasil. (2002). Estatuto da criança e do adolescente (ECA) (12a ed). São Paulo: Saraiva.

Heller, S. S., Boris, N. W., Fuselier, S. H., Page, T., Karie, N. K., \& Miron, D. (2006). Reactive Attachment Disorder in maltreated twins follow-up: From 18 months to 8 years. Attachment and Human Development, 8(1), 63-86.

Kolck, O. L. van. (1994). Testes projetivos gráficos no diagnóstico psicológico. São Paulo: EPU.

Koppitz, E. M. (1968). Psychological evaluation of children's human figure drawings. New York: Grune \& Straton.

Laak, J. T. E. R., Goede, M. D. E., Aleva, A., \& Rijswijk, P. (2005). The draw-a-person test: An indicator of children's cognitive and socioemotional adaptation? The Journal of Genetic Psychology, 166(1), 77-93.

Lim-Hui, K., \& Slaughter, V. (2008). Brief report: Human figure drawings by children with Asperger's syndrome. Journal of Autism and Developmental Disorders, 38(5), 988-994.

Mukaddes, N. H., Bilge, S., Alyanak, B., \& Kora, M. E. (2000). Clinical characteristics and treatment responses in cases diagnosed as reactive attachment disorder. Child Psychatry and Human Development, 30(4), 273-287.

Orionte, I., \& Sousa, S. M. G. (2005). O significado do abandono para crianças institucionalizadas. Psicologia em Revista, 11(17), 29-46.

Parreira, S. M. C. P., \& Justo, J. S. (2005). A criança abrigada: Considerações acerca do sentido da filiação. Psicologia em Estudo, 10(2), 175-180.
Schwartz, E., \& Davis, A. S. (2006). Reactive attachment disorder: Implications for school readiness and school functioning. Psychology in the Schools, 43(4), 471-479.

Siqueira, A. C., \& Dell'Aglio, D. D. (2006). 0 impacto da institucionalização na infância e na adolescência: Uma revisão de literatura. Psicologia \& Sociedade, 18(1), 71-80.

Sisto, F. F., \& Rueda, F. J. M. (2006). Estudando sobre as categorias de interpretação das Matrizes Coloridas e Raven e DFH - Escala SISTO. Aletheia, 23, 17-26.

Smyke, A.T., Dumitrescu, A., \& Zeanah, C. H. (2002). Attachment disturbances in young children. I: The continuum of caretaking casualty. Journal of the American Academy of Child and Adolescent Psychiatry, 41(8), 972-982.

Tharinger, D. I., \& Stark, K. (1990). A qualitative versus quantitative approach to evaluating the draw-a-person and kinetic family drawing: A study of mood- and anxiety-disorder children. Psychological Assessment: A Journal of Consulting and Clinical Psychology, 2(4), 365-375.

Vargas, M. M. (1998). Adoção tardia: Da família sonhada à família possível. São Paulo: Casa do Psicólogo.

Weber, L. N. D. (1995). Da institucionalização à adoção: Um caminho possível? Revista Igualdade, 9, 1-8.

Wechsler, S. M., \& Schelini, P. W. (2002). Validade do desenho da figura humana para avaliação. Avaliação Psicologica, 1, 29-38.

Zeanah, C. H., \& Smyke, A. T. (2008). Attachment disorders in family and social context. Infant Mental Health Journal, 29(3), 219-233. 